\title{
ИССЛЕДОВАНИЕ АЭРОДИНАМИЧЕСКИХ ПАРАМЕТРОВ РУДНИЧНЫХ ВЕНТИЛЯЦИОННЫХ СЕТЕЙ ДЛЯ ОПРЕДЕЛЕНИЯ ПАРАМЕТРОВ РЕЦИРКУЛЯЦИОННОГО ПРОВЕТРИВАНИЯ
}

\author{
Н.А. Трушкова \\ Горный институт УрО РАН, г. Пермь
}

\begin{abstract}
Аннотация: Рециркуляционные системы применяются для повышения эффективности проветривания рудников. В настоящее время основным параметром, определяемым при расчете рециркуляционных систем, является количество повторно используемого воздуха, которое зависит от количества выделяющихся газов. На эффективность и безопасность применения рециркуляционных систем также значительное влияние оказывают аэродинамические параметры вентиляционной сети, такие, как сопротивление участков вентиляционной сети и величина утечек внутри рециркуляционного контура. В данной работе приведены результаты исследований аэродинамических параметров вентиляционных сетей различных рудников.
\end{abstract}

Ключевые слова: рециркуляция, коэффициент рециркуляции, аэродинамическое сопротивление, утечки воздуха, свежая струя, исходящая струя.

Рециркуляционное проветривание заключается в повторном использовании части отработанного воздуха, который за счет работы рециркуляционной установки смешивается со свежим воздухом и подается на проветривание рабочих зон. Контролируемая рециркуляция применяется для снижения энергопотребления главных вентиляторных установок, снижения затрат на обогрев воздуха в холодное время года и улучшения микроклиматических условий в подземных горных выработках. Основными требованиями, предъявляемыми к рециркуляционным системам, являются безопасность и эффективность их применения.

Много исследований зарубежных ученых посвящено вопросам применения рециркуляции на различных рудниках [1-4], в результате устанавливается эффективность и безопасность применения частичного повторного использования воздуха. В исследованиях российских ученых также рассматривается вопрос применения рециркуляции на калийных рудниках. В работе [5] приведены результаты исследований, доказывающих возможность применения рециркуляции на калийных рудниках за счет сорбционных свойств массива, обеспечивающих промежуточную очистку воздуха и результаты измерений газового состава рудничного воздуха на исходящей струе. В исследованиях $[6,8]$ установлено, что нет опасности непрерывного накопления газов в рециркуляционном контуре, а в работе [7] отражены результаты исследований газового состава рудничного воздуха по маршруту движения воздуха от воздухоподающего ствола до вентиляционного через рабочие зоны, где и происходит выделение вредных газов. Результат исследований на калийных и полиметаллических рудниках показал, что исходящая струя пригодна для повторного использования, а превышения концентрации газов выше допустимых значений происходит только в ситуациях, связанных с нарушением проветривания.

При выборе параметров работы рециркуляционных систем следует руководствоваться условиями эффективности и безопасности их работы. Безопасность применения рециркуляционных систем в значительной степени зависит от корректности определения количества повторно используемого воздуха. Эффективность работы рециркуляционных систем зависит от места их размещения.

На калийных рудниках России и Беларуси применяются рециркуляционные системы, но подходы к расчету количества повторно используемого воздуха разные. На руд- 
никах Верхнекамского месторождения [9] количество повторно используемого воздуха определяется коэффициентом рециркуляции, который в свою очередь зависит от концентрации газов в месте размещения рециркуляционной установки и коэффициента, учитывающего тип выделяемых вредностей. Также регламентируется максимальное количество повторно используемого воздуха - 70\%.

На рудниках Старобинского месторождения [10] количество повторно используемого воздуха для рабочей зоны определяется с учетом требуемого количества воздуха по газовому фактору и величины утечек. Далее для более крупных участков шахтного поля количество повторно используемого воздуха определяется как сумма утечек воздуха на участке и количества повторно используемого воздуха. Максимальное количество повторно используемого воздуха ограничено величиной требуемого расхода воздуха по газовому фактору.

Таким образом, в существующих методиках при расчете количества повторно используемого воздуха учитывается количество вредных газов в исходящей струе и величина утечек воздуха на рассматриваемом участке. Но эти параметры учтены в данных методиках не в полной мере, при расчетах необходимо учитывать и качество воздуха на исходящей струе и величину утечек внутри рециркуляционного контура, так как это оказывает значительное влияние на безопасность применения рециркуляционных систем.

Целесообразность применения и эффективность работы рециркуляционных систем зависит от места их размещения и, следовательно, от сопротивления участков вентиляционной сети до и после рециркуляционной выработки.

Не вполне корректно считать, что применение рециркуляционных систем эффективно и целесообразно на всех без исключения рудниках. Для оценки целесообразности применения рециркуляции проведены исследования аэродинамических параметров вентиляционных сетей различных рудников. К аэродинамическим параметрам вентиляционных сетей относятся расход воздуха и перепады давления на участках вентиляционной сети. К параметрам рециркуляционного проветривания относятся количество повторно используемого воздуха и место размещения рециркуляционной установки.

Аэродинамические параметры участков вентиляционной сети определяются на основании данных воздушно-депрессионных съемок. При отсутствии данных натурных исследований необходимые величины могут быть вычислены по следующим формулам: [1-6].

$$
\begin{gathered}
H_{\text {Гву }}=\sum H_{\text {ств }}+\bar{H}_{\text {кан.Гву }} \\
Q_{\text {Гву }}=Q_{\text {кан.Гву }}=Q_{\text {рудд }}+Q_{\text {внеш.ут }} \\
\sum H_{\text {ств }}=\bar{H}_{\text {вент.ств }}+\bar{H}_{\text {возд.ств }} \\
H_{\text {подз }}=\bar{P}_{\text {св }}-\bar{P}_{\text {исх }} \\
Q_{\text {руд }}=Q_{\text {вент.ств }}=\sum Q_{\text {потр }}+\sum Q_{\text {вн.ут }} \\
K_{\text {ут }}=\frac{Q_{\text {руд }}}{Q_{\text {руд }}-\sum Q_{\text {вн.ут }}}
\end{gathered}
$$

где $H_{\text {Гву }}$ - депрессия, развиваемая главной вентиляторной установкой, Па; $\sum H_{\text {ств }}-$ сумма перепадов давления на воздухоподающих и вентиляционном стволе, Па; $\bar{H}_{\text {кан.Гву }}$ - средняя величина перепада давления в каналах главных вентиляторных установок, Па; $H_{\text {подз }}$ - депрессия подземной части рудника, исключая стволы, Па; $\bar{P}_{\text {св }}$ средняя величина приведенного давления на сопряжениях воздухоподающих стволов с выработками горизонта, Па; $\bar{P}_{\text {исх }}$ - средняя величина приведенного давления на сопряжении вентиляционных стволов с выработками горизонта, Па; $Q_{\Gamma в у}-$ производительность главной вентиляторной установки, $\mathrm{m}^{3} / \mathrm{c} ; Q_{\text {кан.Гву }}-$ расход воздуха в канале главной вентиляторной установки, ${ }^{3} / \mathrm{c} ; Q_{\text {руд }}-$ количество воздуха, поступающее в рудник, 
$\mathrm{m}^{3} / \mathrm{c} ; Q_{\text {вент.ств }}$ - количество воздуха, проходящее по вентиляционному стволу, $\mathrm{m}^{3} / \mathrm{c}$; $\sum Q_{\text {потр }}$ - суммарное количество воздуха на потребителях (забои, рабочие зоны и камеры служебного назначения), $\mathrm{m}^{3} / \mathrm{c} ; \sum Q_{\text {вн.ут }}$ - суммарное количество внутренних утечек воздуха, ${ }^{3} / \mathrm{c} ; Q_{\text {внеш.ут }}-$ количество внешних утечек воздуха, ${ }^{3} / \mathrm{c} ; K_{\text {ут }}-$ коэффициент внутренних утечек воздуха утечек воздуха, ${ }^{3} / \mathrm{c}$.

На первоначальном этапе выполнены исследования вентиляционных сетей калийных рудников Верхнекамского месторождения.

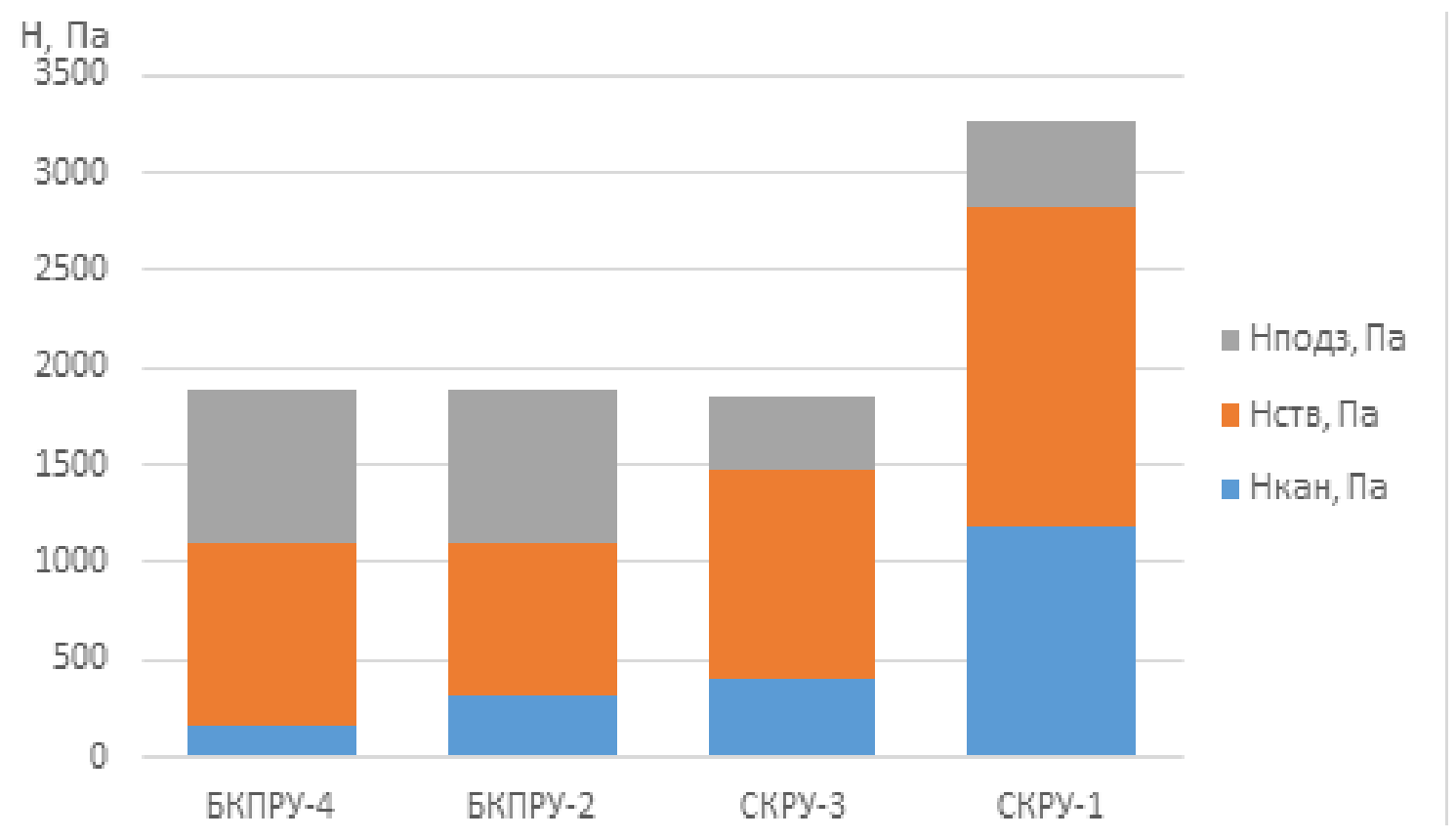

Рис. 1. Результат измерения аэродинамических параметров на рудниках Верхнекамского месторождения

Величина коэффициента внутренних утечек варьируется от 1,248 до 1,544.

Результаты измерений, представленные на рисунке 1, показывают, что основная часть депрессии, развиваемой главной вентиляторной установкой, затрачивается на преодоление сопротивления стволов и вентиляционного канала. Это говорит о том, что работа рециркуляционных систем эффективна в данных условиях.

Аналогичные исследования выполнены на рудниках месторождения Норильского района и Талнахского месторождения, результаты измерений приведены на рисунках 2 и 3 соответственно.

Величина коэффициента внутренних утечек варьируется от 1,76 до 2,66 на рудниках Норильского района и от 1,2 до 1,52 на рудниках Талнахского месторождения.

Результаты натурных исследований позволили определить величину внутренних утечек воздуха, это даст возможность далее скорректировать методику и учитывать величину утечек при расчете количества повторно используемого воздуха.

Результат исследований аэродинамических параметров показал, что на большинстве рассматриваемых рудников основная часть депрессии, развиваемой ГВУ, затрачивается на преодоление сопротивления вскрывающих выработок и вентиляционных каналов. Это говорит о том, что на всех рудниках, где депрессия подземной части рудника меньше депрессии вскрывающих выработок, применение рециркуляционного проветривания целесообразно и эффективно. 


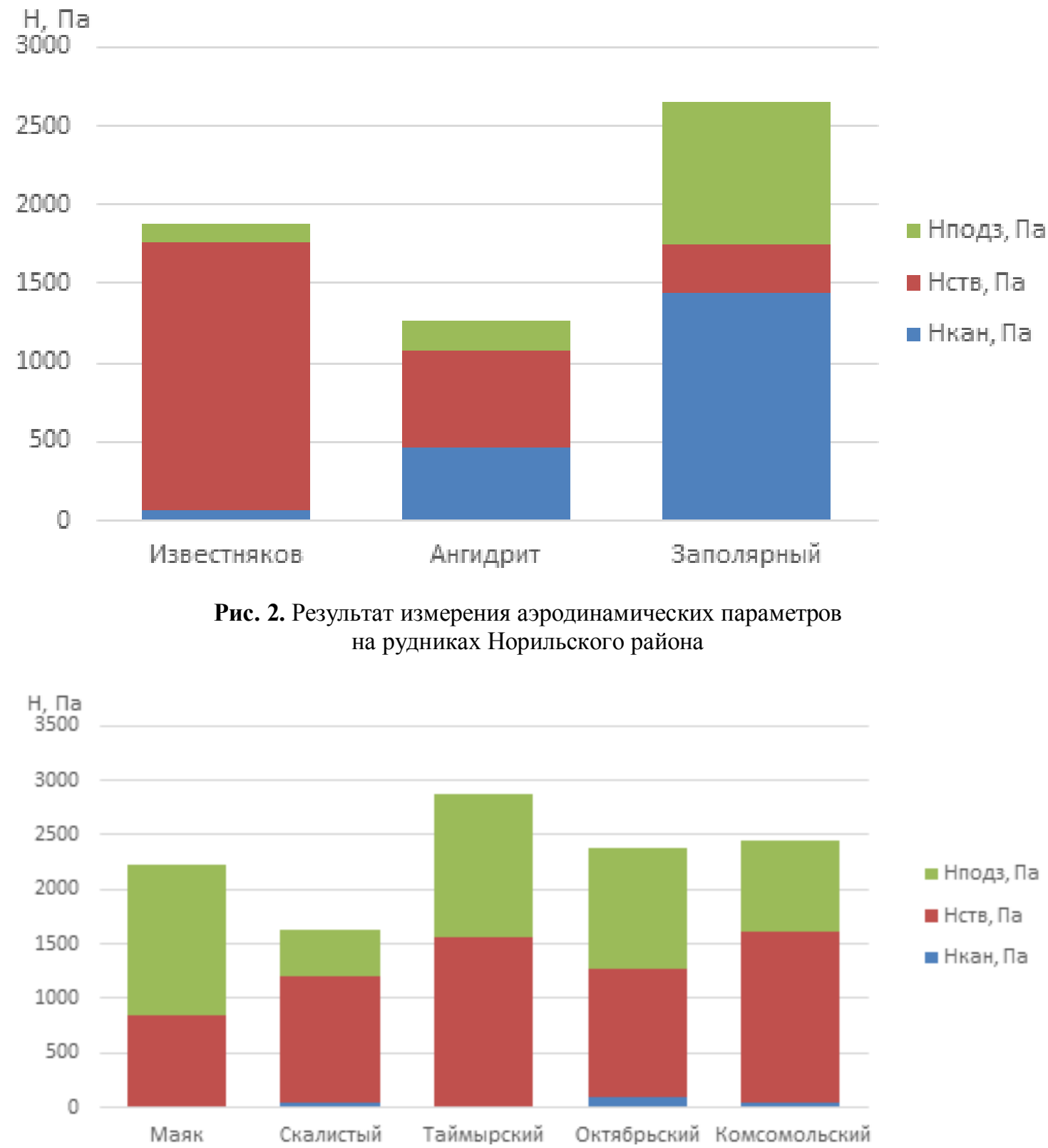

Рис. 3. Результат измерения аэродинамических параметров на рудниках Талнахского месторождения

\section{БИБЛИОГРАФИЧЕСКИЙ СПИСОК}

1. Hall A.E., McHaina D.M., Hardcastle S. Controlled recirculation in Canadian underground potash mines // Mining Science and Technology. - 1990. - V. 10, № 3. - P. 305-314.

2. Pritchard C., Scott D., Frey G., Case study of controlled recirculation at a Wyoming trona mine // Trans Soc Min Metall Explor Inc. - 2013. - V. 334, № 1. - P. 444-448. - PMC 4524347.

3. Meyer C.F. Controlled recirculation of mine air in a South African colliery // Proceedings of the $6^{\text {th }}$ US Mine Ventilation Symposium. - Salt Lake City, UT, USA, 1993. - P. 25-29.

4. Wu H.W., Gillies A.D.S., Nixon A.C., Trial of controlled partial recirculation of ventilation air at Mount Isa Mines // Institution of Mining and Metallurgy. Transactions. Section A: Mining Technology. - 2001. - V. 110, № May/Aug. - P. A86-A96.

5. Медведев И.И., Красноштейн А.Е. Аэрология калийных рудников / УрО АН СССР. - Свердловск, 1990. -251 с.: ил. 
6. Казаков Б.П. Повышение эффективности ресурсосберегающих систем вентиляции для подземных рудников / Б.П. Казаков, Л.Ю. Левин, А.В. Шалимов // Горн. журн. - 2014. - № 5. - С. 26-28.

7. Трушкова Н.А. Исследование газового состава рудничного воздуха для оценки возможности применения рециркуляционного проветривания // Горное эхо. - 2019. - № 3 (76). - С. 84-87. DOI: 10.7242/echo.2019.3.23.

8. Казаков Б.П., Исаевич А.Г., Шалимов А.В. Проветривание калийных рудников с частичным повторным использованием // Изв. вузов. Горн. журн. - 2007. - № 4 . - С. 47-52.

9. Технологический регламент по организации проветривания рудников ОАО «Уралкалий». - ПермьБерезники-Соликамск, 2013г.

10. Инструкция по расчету количества воздуха, необходимого для проветривания рудников Старобинского месторождения. - Минск-Солигорск-Пермь, 2018. 